\title{
Impact of COVID-19 on cardiovascular diseases: considerations for patients and healthcare systems
}

\author{
Zu Jiang ${ }^{1 *}$, Xu Ting ${ }^{2}$, Ping $\mathrm{Ji}^{3}$, Hu Zhanwei ${ }^{4}$, Shen $\mathrm{Li}^{4}$ \\ ${ }^{1}$ Medical College, Qinghai University, Xining, Qinghai, China \\ ${ }^{2}$ Xinjiang Medical University, Xinjiang, China \\ ${ }^{3}$ College of pharmacy, Qinghai University, Xining, Qinghai, China \\ ${ }^{4}$ Jinzhou Medical University, Jinzhou, China
}

*Corresponding author: Medical College, Qinghai University, Xining, Qinghai, China, Email address: zu.jiang78@gmail.com

\begin{abstract}
Coronavirus disease 2019 (COVID-19) is caused by severe acute respiratory syndrome coronavirus 2 (SARS-CoV-2). It mostly presents with fevers and respiratory symptoms that can progress from simple pneumonia to severe acute respiratory distress syndrome (ARDS). It also has significant implications for the cardiovascular care of patients. Troponin, which is a sign of cardiac injury, usually goes up in patients who are hospitalized, and it requires careful consideration. Microvascular activation by cytokines might cause myocardial damage, and it can harm other organs usually involved in COVID-19, such as lungs and kidneys. COVID-19 infection is also associated with venous thromboembolism, arrhythmias, and myocarditis. On the other hand, the cardiovascular care provision might position workers in the healthcare system in vulnerability once they become hosts or vectors for the transmission of coronavirus. In this study, we have investigated the articles on cardiovascular considerations concerning COVID-19 and then introduced the gaps which require more investigation pertinent to patients and healthcare systems.
\end{abstract}

Keywords: COVID-19; SARS-CoV-2; cardiovascular disease; atherosclerosis; healthcare 


\section{Introduction}

Severe acute respiratory syndrome coronavirus 2 (SARS-CoV-2), a new strain of coronavirus, causes coronavirus disease 2019 (COVID-19) [1, 2]. It was first reported in China in late 2019 and spread rapidly worldwide [3-5]. The symptoms of COVID-19 are dry cough, high temperature, headache, tiredness, shortness of breath, loss of taste or smell, and gastrointestinal symptoms such as abdominal pain, anorexia, nausea, diarrhea. Increased liver enzyme and low counts of lymphocytes (lymphocytopenia) along with increased C-reactive protein (CRP) levels existed in patients with COVD-19 [5-7]. This disease could eventually lead to acute respiratory distress syndrome (ARDS) [6].

It was originally thought novel coronavirus was mainly a respiratory disorder, but as a great number of patients received the virus, it became obvious that it has many other physiological manifestations. The influence of COVID-19 goes well beyond the lungs to impact the cardiovascular system and cause complications in the brain, kidneys, and other organs. Based on reports that showed a strong relationship between increased D-dimer levels and weak prognosis, concerns have appeared about thrombotic complications in COVID-19 patients [8-10]. The National Institute for Public Health of the Netherlands suggests a respiratory failure in COVID-19 is not caused only by the development of acute respiratory distress syndrome, but that microvascular thrombotic processes might have an impact [11].

Treatment of COVID-19 infections consisted of new, standard, and experimental therapies. Particular antiviral, anti-inflammatory, immunosuppressive, and cell-based therapies carry on to change [12]. Nonetheless, it is suggested that a considerable number of patients who survive COVID-19 and have verification for myocardial issues at the time of the first presentation might have lasting overt or subclinical myocardial or electrophysiological disorders. It is not known whether the intensity of the cardiopulmonary injury, treatment type, or other factors impact lasting sequelae. Heightened observation is, accordingly, validated in these patients with consideration of foremost prevention approaches. Although the COVID-19 infection is novel, there have been many case series and review articles on cardiovascular complications during the COVID-19 infection. In this paper, the potential cardiovascular complications that might happen during the 
recovering phase in the COVID-19 survivors, as well as considerations for the health system, are discussed.

\section{Severe Acute Respiratory Syndrome Coronavirus}

The Severe Acute Respiratory Syndrome Coronavirus (SARS-CoV) outbreak started in the Guangdong Province, southern China in 2002, and was most probably connected to a zoonotic event in the market of wild animals [13-15]. The SARS-CoV is one of the $\beta$-CoVs group viruses and ties to the zinc peptidase angiotensin-converting enzyme 2 (ACE2), a molecule that is put on the endothelial cells of artery and veins surfaces, epithelia of the small intestine, respiratory tract epithelium, respiratory tract epithelium, arterial smooth muscle, and immune cells, to enter the host cell [16]. Subduing of ACE2 expression during the infection of SARS-CoV has been suggested to have an impact on the pathologic variations in the lung and cause severe pneumonia and acute lung failure seen with this virus [17-20].

More investigations of wild animals show robust evidence that SARS-CoV may have come from bats when a SARS-like CoV was found in Chinese horseshoe bats with a sequence resemblance of $87 \%$ to $92 \%$ with human SARS-CoV [21]. It has also been alleged that raccoon dogs and palm civets prepared the intermediate amplification host for SARS-CoV before spreading it to animal handlers in the animal market $[22,23]$. The spread of SARS-CoV is mainly from people to people who are in contact, through respiratory droplets, with an incubation period of 2 to 14 days after exposure [5]. The SARS-CoV might be spread into the atmosphere and transmitted from surfaces to the hands of people who are patient and health care system clinicians. In this regard, the synergic effects of anionic surfactants on coronavirus have been studied to improve the virucidal efficiency of commonly used sanitizers [24]. Transmission of infection can be performed via contact with the eyes, nose, and mouth. The ability of a patient who is infected to transmit the virus to other people is assessed by R0 (i.e., R naught: basic reproduction number). The approximate R0 for SARS-CoV is about 3, that means each person with SARS-CoV is anticipated to be able to infect three other individuals in a vulnerable population [25]. 


\section{Atherosclerotic lesion}

Arteriosclerosis happens when the blood vessels that transfer oxygen and nutrients from heart to the remainder of the body (arteries) become stiff and thick. It often limits blood flow to the tissues and organs. Healthy arteries are pliant and elastic, but when time passes, the walls in the arteries could stiffen, a situation usually called hardening of the arteries. Atherosclerosis refers to the growth of cholesterol, fats, and other substances in and on the artery walls (plaque), that can limit the blood flow [26]. Atherosclerosis mostly forms in left main coronary bifurcation to left anterior descending (LAD) and left circumflex (LXC) branches [10]. The plaque in the arteries, can rupture, prompting a blood clot. Although atherosclerosis is mostly considered a heart issue, it could impact the arteries anywhere in the body. Clinically, given the expansion of the arteries, symptomatic atherosclerosis is usually related to males in their 40s and females in their 50s to $60 \mathrm{~s}$ [27]. Sub-clinically, the illness starts to appear in childhood and seldom is already present at birth. Perceptible signs could start developing at puberty. Though symptoms are seldom shown in children, early screening of children for cardiovascular illnesses can be useful to the children and also their relatives [28].

The demographic mostly affected by lethal COVID-19 has a high prior likelihood of formed atherosclerotic lesions: they are old people, mainly male, and have underlying lung disease, including that related to cigarette smoking, a risk factor for atherosclerosis. Distant infections such as the severe pneumonitis that too frequently complicates COVID-19 could obtain an acute irritation of the chronic smoldering inflammation that marks coronary atherosclerotic lesions [29]. The inflammatory cells at a location of zonal infection such as the lungs in COVID-19 pneumonitis could cause cytokines such as interleukin-1 and -6 and tumor necrosis factor to be produced, mediators that not only disseminate regional inflammation but could enter the systemic circulation [30]. These circulating cytokines could prompt macrophages in the plaque to increase the production of regional cytokine and arouse a growth in tissue factor expression that makes lesions more thrombogenic. We have referred to this local response to systemic stimuli as an "echo" event. These same systemic cytokines could trigger leukocyte adhesion molecule expression on the endothelial cells overspreading established atheroma, increasing regional recruitment of these inflammatory cells. These changes in underlying plaques could intensify their tendecy to disturb, 
be it by fibrous cap fissure or by external erosion, and stimulate an acute coronary syndrome [31, 32].

\section{Sars-CoV-2 impacts on Cardiovascular System}

A schematic of the impact of SARS-CoV-2 on the cardiovascular system is shown in Fig. 1. It has been observed that patients with coronary artery disease (CAD) are susceptible to develop adverse outcomes and death because of COVID-19 [33-35]. As shown in previous studies, for other acute infections, the hyperdynamic circulation resulted from COVID-19 in patients with liable factors for $\mathrm{CAD}$ might aggravate the dangerous balance by increasing the demand for myocardial oxygen, bringing about acute coronary syndrome (ACS) $[36,37]$. ACS in patients who are infected might be caused by immoderate cytokines causing atherosclerotic plaque instability and rupture [33]. A case report on a man who was 70-year-old was published. He was cured three years before by percutaneous coronary intervention (PCI) and infected by COVID-19, who showed up with ACS and non-ST segment elevation myocardial infarction (NSTEMI). The angiogram of coronary depicted atherosclerotic spontaneous coronary artery dissection (A-SCAD) on the coronary artery and proximal left anterior descending (LAD) and in-stent restenosis of a marginal branch (OM) [38].

The impact of coronavirus on lipid metabolism and development of the atherosclerotic procedure is verified by an observational study carried out to examine long-term e_ects of infection of acute Sars-CoV [39]. Twenty-five patients were enlisted 13 years after healing from Sars-CoV in 2003. The metabolomic examination was conducted, depicting a changed lipid metabolism with remarkably elevated amounts of free fatty acids, lysophosphatidylethanolamine, lysophosphatidylcholine and phosphatidylglycerol. In addition, 44\% of the patients were a_ected by CVD. Sars-CoV pathogenesis depicts a significant resemblance to COVID-19, being marked by an unusual hyperactivation of the immune system, causing extra amounts of cytokines [40, 41]. Hyperactivation of pro-inflammatory patterns, primarily identified by cytokine storm, might augment the possibility of restenosis in patients who experienced PCI with stent implantation because of CHD. Pre-operative elevated extents of IL-6, TNF-_, and IL-23 might e_ciently 
anticipate the risk of restenosis after PCI related to the implantation of drug-eluting stent (DES) [42].

In addition to ACS, the cardiovascular system might be complicated in patients a_ected by heart failure because of hemodynamic decompensation and, in a little percentage of patients, acute myocarditis might happen without earlier confirmation of CVD because of the presence of ACE2 on cardiac myocytes, potentially causing chronic dilated cardiomyopathy [43-46].

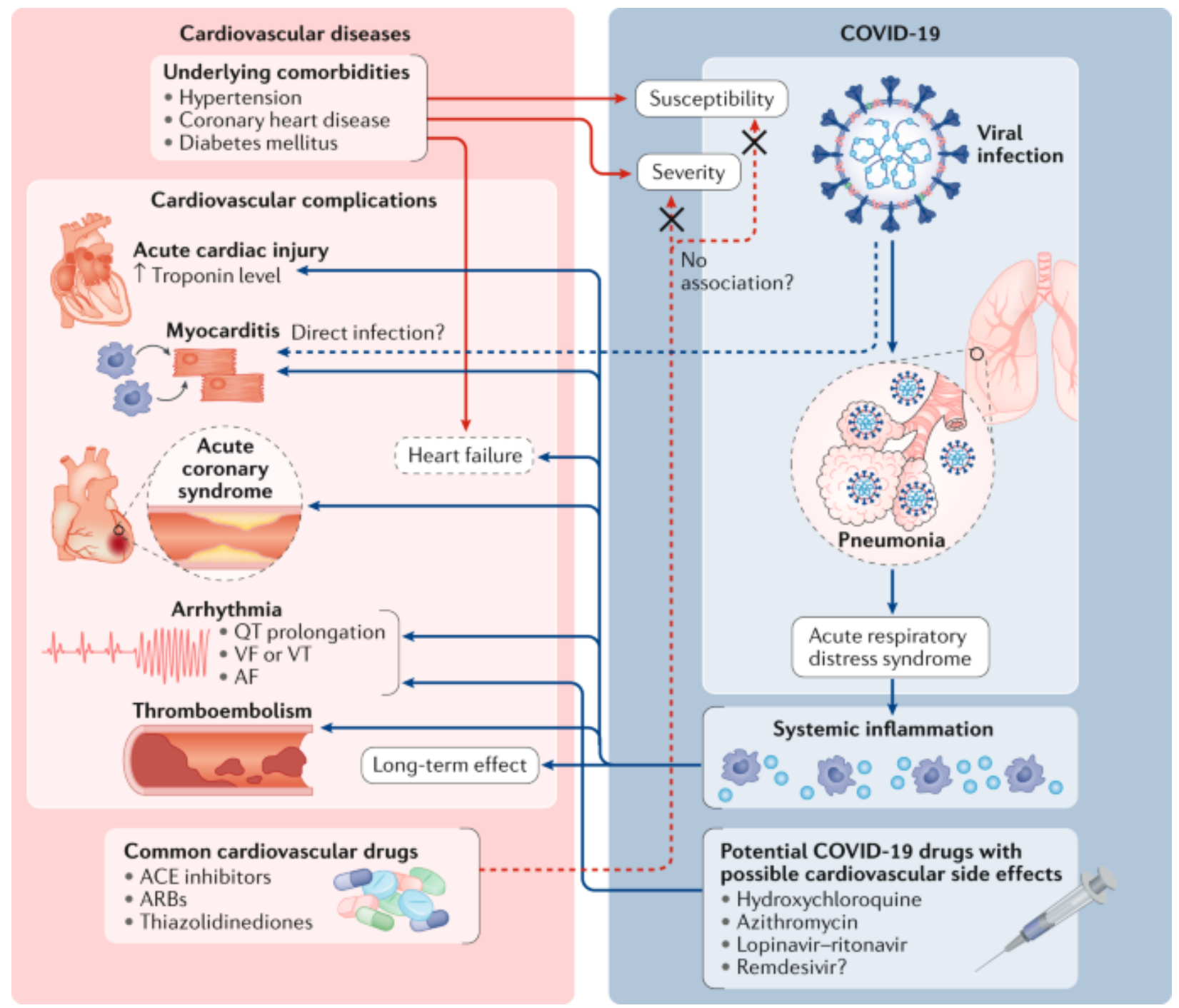

Figure 1. Schematic of the impact of SARS-CoV-2 on the cardiovascular system 
Potentially, the long-term e_ects of cardiovascular system involvement, primarily because of hemodynamic changes, atherosclerotic development, and causing an increased risk of thrombosis because of COVID-19, might directly influence the function of left ventricular systolic and elevate retrograde pressure on the right cardiac chambers resulting in decompensation. Increased occurrence of deep vein thrombosis (DVT) events because of abnormal blood clotting might result in more pulmonary hypertension and pulmonary embolism events [47-49].

\section{Conclusions and future directions}

The COVID-19 disease has impacted thousands of patients who are suffering from cardiovascular diseases such as atherosclerosis and causes a significant health warning on an international scale. The management and handling of patients who are impacted by this disease are crucial in addition to providing continuousness of care to patients who are not infected with pre-existing CVD. In the upcoming months, attempts for evaluating new therapies would be important to the healing of coronavirus, and as this procedure progresses, more recognition of the complex interplay among COVID-19, CVD, and the different stakeholders who are involved including patients, and health care systems, would be vital to developing results in at-risk and patients who are infected [50-52]. Potential unarranged clinical trials and group studies are ongoing and would be vital to helping heal patients who are impacted by this coronavirus.

A number of theories exist regarding the elevated risk of adverse events for patients with CVD who develop COVID-19. Particularly, good apprehension of the association engaging the ACE2 protein, antihypertensive agent use, and COVID-19 prognosis would have crucial implications for patients with both CVD and COVID-19. Outside of the area of individual trials, concerted attempts by all workers in the health care system and insightful control are needed to assist in alleviating the health risk to the at large, in addition to workers in $\mathrm{CV}$ health care, as shown by the hard decision to cancel the Scientific Sessions of 2020 American College of Cardiology. Organized use of assets, such as using the telehealth capacities and appropriate adhesion to preventative population-wide and measures of health care worker-level, would enable the move from this critical time till the disease outbreak is contained. 


\section{References}

1. Zu ZY, Jiang MD, Xu PP, Chen W, Ni QQ, Lu GM, et al. Coronavirus disease 2019 (COVID-19): a perspective from China. Radiology. 2020:200490. https://doi.org/10.1148/radiol.2020200490

2. Fauci AS, Lane HC, Redfield RR. Covid-19-navigating the uncharted. Mass Medical Soc; 2020. https://doi.org/10.1056/NEJMe2002387

3. Dong Y, Mo X, Hu Y, Qi X, Jiang F, Jiang Z, et al. Epidemiology of COVID-19 among children in China. Pediatrics. 2020;145(6). https://doi.org/10.1542/peds.2020-0702

4. Novel CPERE. The epidemiological characteristics of an outbreak of 2019 novel coronavirus diseases (COVID-19) in China. Zhonghua liu xing bing xue za zhi= Zhonghua liuxingbingxue zazhi. 2020;41(2):145. https://doi.org/10.3760/cma.j.issn.0254-6450.2020.02.003

5. Lauer SA, Grantz KH, Bi Q, Jones FK, Zheng Q, Meredith HR, et al. The incubation period of coronavirus disease 2019 (COVID-19) from publicly reported confirmed cases: estimation and application. Annals of internal medicine. 2020;172(9):577-82. https://doi.org/10.7326/M20-0504

6. Jahromi R, Avazpour A, Jahromi M, Alavi J. COVID-19 with positive bronchoalveolar lavage fluid but negative nasopharyngeal and oropharyngeal swabs: A case report and insights. Indian Journal of Case Reports. 2020:380-2. https://doi.org/10.32677/IJCR.2020.v06.i07.010

7. Zhai P, Ding Y, Wu X, Long J, Zhong Y, Li Y. The epidemiology, diagnosis and treatment of COVID-19. International journal of antimicrobial agents. 2020:105955. https://doi.org/10.1016/j.ijantimicag.2020.105955

8. Clerkin KJ, Fried JA, Raikhelkar J, Sayer G, Griffin JM, Masoumi A, et al. COVID-19 and cardiovascular disease. Circulation. 2020;141(20):1648-55. https://doi.org/10.1161/CIRCULATIONAHA.120.046941

9. Puntmann VO, Carerj ML, Wieters I, Fahim M, Arendt C, Hoffmann J, et al. Outcomes of cardiovascular magnetic resonance imaging in patients recently recovered from coronavirus $\begin{array}{lllll}\text { disease } & 2019 & \text { (COVID-19). } & \text { JAMA } & \text { cardiology. }\end{array}$ https://doi.org/doi:10.1001/jamacardio.2020.3557

10. Jahromi R, Pakravan HA, Saidi MS, Firoozabadi B. Primary stenosis progression versus secondary stenosis formation in the left coronary bifurcation: A mechanical point of view. $\begin{array}{llll}\text { Biocybernetics and } \quad \text { Biomedical } & \text { Engineering. }\end{array}$ https://doi.org/10.1016/j.bbe.2018.11.006

11. Oudkerk M, Büller HR, Kuijpers D, van Es N, Oudkerk SF, McLoud TC, et al. Diagnosis, prevention, and treatment of thromboembolic complications in COVID-19: report of the National Institute for Public Health of the Netherlands. Radiology. 2020:201629. https://doi.org/10.1148/radiol.2020201629 
12. Zhu L, Xu X, Ma K, Yang J, Guan H, Chen S, et al. Successful recovery of COVID-19 pneumonia in a renal transplant recipient with long-term immunosuppression. American Journal of Transplantation. 2020. https://doi.org/10.1111/ajt.15869

13. Lau SK, Woo PC, Li KS, Huang Y, Tsoi H-W, Wong BH, et al. Severe acute respiratory syndrome coronavirus-like virus in Chinese horseshoe bats. Proceedings of the National Academy of Sciences. 2005;102(39):14040-5. https://doi.org/10.1073/pnas.0506735102

14. Zhang $\mathrm{T}, \mathrm{Wu} \mathrm{Q}$, Zhang Z. Probable pangolin origin of SARS-CoV-2 associated with the COVID-19 outbreak. Current Biology. 2020. https://doi.org/10.1016/j.cub.2020.03.022

15. Ivanov D. Predicting the impacts of epidemic outbreaks on global supply chains: A simulation-based analysis on the coronavirus outbreak (COVID-19/SARS-CoV-2) case. Transportation Research Part E: Logistics and Transportation Review. 2020;136:101922. https://doi.org/10.1016/j.tre.2020.101922

16. Xia S, Liu M, Wang C, Xu W, Lan Q, Feng S, et al. Inhibition of SARS-CoV-2 (previously 2019-nCoV) infection by a highly potent pan-coronavirus fusion inhibitor targeting its spike protein that harbors a high capacity to mediate membrane fusion. Cell research. 2020;30(4):34355. https://doi.org/10.1002/jmv.20556

17. Okabayashi T, Kariwa H, Yokota Si, Iki S, Indoh T, Yokosawa N, et al. Cytokine regulation in SARS coronavirus infection compared to other respiratory virus infections. Journal of medical virology. 2006;78(4):417-24. https://doi.org/10.1002/jmv.20556

18. Korber B, Fischer WM, Gnanakaran S, Yoon H, Theiler J, Abfalterer W, et al. Tracking changes in SARS-CoV-2 Spike: evidence that D614G increases infectivity of the COVID-19 virus. Cell. 2020;182(4):812-27. e19. https://doi.org/10.1016/j.cell.2020.06.043

19. Ni L, Ye F, Cheng M-L, Feng Y, Deng Y-Q, Zhao H, et al. Detection of SARS-CoV-2specific humoral and cellular immunity in COVID-19 convalescent individuals. Immunity. 2020. https://doi.org/10.1016/j.immuni.2020.04.023

20. ul Qamar MT, Alqahtani SM, Alamri MA, Chen L-L. Structural basis of SARS-CoV-2 3CLpro and anti-COVID-19 drug discovery from medicinal plants. Journal of pharmaceutical analysis. 2020. https://doi.org/10.1016/j.jpha.2020.03.009

21. Shi Z, Hu Z. A review of studies on animal reservoirs of the SARS coronavirus. Virus research. 2008;133(1):74-87. https://doi.org/10.1016/j.virusres.2007.03.012

22. Ye Z-W, Yuan S, Yuen K-S, Fung S-Y, Chan C-P, Jin D-Y. Zoonotic origins of human coronaviruses. International journal of biological sciences. 2020;16(10):1686. https://doi.org/10.7150/ijbs.45472 
23. Dashraath P, Jeslyn WJL, Karen LMX, Min LL, Sarah L, Biswas A, et al. Coronavirus disease 2019 (COVID-19) pandemic and pregnancy. American journal of obstetrics and gynecology. 2020. https://doi.org/10.1016/j.ajog.2020.03.021

24. Jahromi R, Mogharab V, Jahromi H, Avazpour A. Synergistic effects of anionic surfactants on coronavirus (SARS-CoV-2) virucidal efficiency of sanitizing fluids to fight COVID-19. Food and Chemical Toxicology. 2020: 111702. https://doi.org/10.1016/j.fct.2020.111702

25. Chintalapudi N, Battineni G, Amenta F. COVID-19 disease outbreak forecasting of registered and recovered cases after sixty day lockdown in Italy: A data driven model approach. Journal of Microbiology, Immunology and Infection. 2020. https://doi.org/10.1016/j.jmii.2020.04.004

26. Libby P, Ridker PM, Maseri A. Inflammation and atherosclerosis. Circulation. 2002;105(9):1135-43. https://doi.org/10.1161/hc0902.104353

27. Nagai Y, Metter EJ, Earley CJ, Kemper MK, Becker LC, Lakatta EG, et al. Increased carotid artery intimal-medial thickness in asymptomatic older subjects with exercise-induced $\begin{array}{lll}\text { myocardial ischemia. } & \text { Circulation. } & \text { 1998;98(15):1504-9. }\end{array}$ https://doi.org/10.1161/01.CIR.98.15.1504

28. Berenson GS, Srinivasan SR, Bao W, Newman WP, Tracy RE, Wattigney WA. Association between multiple cardiovascular risk factors and atherosclerosis in children and young adults. New England journal of medicine. 1998;338(23):1650-6. https://doi.org/10.1056/NEJM199806043382302

29. South AM, Diz DI, Chappell MC. COVID-19, ACE2, and the cardiovascular consequences. American Journal of Physiology-Heart and Circulatory Physiology. 2020. https://doi.org/10.1152/ajpheart.00217.2020

30. Tian S, Hu W, Niu L, Liu H, Xu H, Xiao S-Y. Pulmonary pathology of early phase 2019 novel coronavirus (COVID-19) pneumonia in two patients with lung cancer. Journal of Thoracic Oncology. 2020. https://doi.org/10.1016/j.jtho.2020.02.010

31. Kume T, Okura H, Kawamoto T, Akasaka T, Toyota E, Watanabe N, et al. Relationship between coronary remodeling and plaque characterization in patients without clinical evidence of

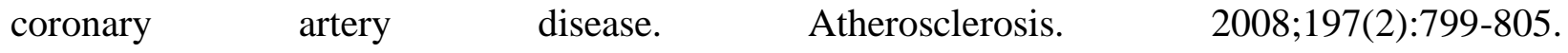
https://doi.org/10.1016/j.atherosclerosis.2007.07.028

32. Zieske AW, Malcom GT, Strong JP. Natural history and risk factors of atherosclerosis in children and youth: the PDAY study. Pediatric pathology \& molecular medicine. 2002;21(2):21337. https://doi.org/10.1080/pdp.21.2.213.237

33. Bonow RO, Fonarow GC, O'Gara PT, Yancy CW. Association of coronavirus disease 2019 (COVID-19) with myocardial injury and mortality. JAMA cardiology. 2020. https://doi.org/10.1001/jamacardio.2020.1105 
34. Katsiki N, Banach M, Mikhailidis DP. Lipid-lowering therapy and renin-angiotensinaldosterone system inhibitors in the era of the COVID-19 pandemic. Archives of Medical Science: AMS. 2020;16(3):485. https://doi.org/10.5114/aoms.2020.94503

35. Cheng H, Wang Y, Wang GQ. Organ-protective effect of angiotensin-converting enzyme 2 and its effect on the prognosis of COVID-19. Journal of medical virology. 2020. https://doi.org/10.1002/jmv.25785

36. Lei S, Jiang F, Su W, Chen C, Chen J, Mei W, et al. Clinical characteristics and outcomes of patients undergoing surgeries during the incubation period of COVID-19 infection. EClinicalMedicine. 2020:100331. https://doi.org/10.1016/j.eclinm.2020.100331

37. Guo J, Huang Z, Lin L, Lv J. Coronavirus disease 2019 (covid-19) and cardiovascular disease: a viewpoint on the potential influence of angiotensin-converting enzyme inhibitors/angiotensin receptor blockers on onset and severity of severe acute respiratory syndrome coronavirus 2 infection. Journal of the American Heart Association. 2020;9(7):e016219. https://doi.org/10.1161/JAHA.120.016219

38. Garcia S, Albaghdadi MS, Meraj PM, Schmidt C, Garberich R, Jaffer FA, et al. Reduction in ST-segment elevation cardiac catheterization laboratory activations in the United States during COVID-19 pandemic. Journal of the American College of Cardiology. 2020. https://doi.org/10.1016/j.jacc.2020.04.011

39. Devaux CA, Rolain J-M, Colson P, Raoult D. New insights on the antiviral effects of chloroquine against coronavirus: what to expect for COVID-19? International journal of antimicrobial agents. 2020:105938. https://doi.org/10.1016/j.ijantimicag.2020.105938

40. Sun X, Wang T, Cai D, Hu Z, Liao H, Zhi L, et al. Cytokine storm intervention in the early stages of COVID-19 pneumonia. Cytokine \& Growth Factor Reviews. 2020. https://doi.org/10.1016/j.cytogfr.2020.04.002

41. Dinarello CA. Proinflammatory cytokines. Chest. 2000;118(2):503-8. https://doi.org/10.1378/chest.118.2.503

42. Babapulle MN, Eisenberg MJ. Coated stents for the prevention of restenosis: Part II. Circulation. 2002;106(22):2859-66. https://doi.org/10.1161/01.CIR.0000038982.49640.70

43. Muir P, Tilzey A, English T, Nicholson F, Signy M, Banatvala J. Chronic relapsing pericarditis and dilated cardiomyopathy: serological evidence of persistent enterovirus infection. The Lancet. 1989;333(8642):804-7. https://doi.org/10.1016/S0140-6736(89)92270-8

44. Matsumori A, Kawai C. An animal model of congestive (dilated) cardiomyopathy: dilatation and hypertrophy of the heart in the chronic stage in DBA/2 mice with myocarditis caused by encephalomyocarditis virus. Circulation. 1982;66(2):355-60. https://doi.org/10.1161/01.CIR.66.2.355 
45. Jahromi S, Amani E, Movahed S. An improved hybrid continuum-atomistic four-way coupled model for electrokinetics in nanofluidics. Electrophoresis. 2019;40(12-13):1678-90. https://doi.org/10.1002/elps.201800307

46. Likoff MJ, Chandler SL, Kay HR. Clinical determinants of mortality in chronic congestive heart failure secondary to idiopathic dilated or to ischemic cardiomyopathy. The American journal of cardiology. 1987;59(6):634-8. https://doi.org/10.1016/0002-9149(87)91183-0

47. McGonagle D, O'Donnell JS, Sharif K, Emery P, Bridgewood C. Immune mechanisms of pulmonary intravascular coagulopathy in COVID-19 pneumonia. The Lancet Rheumatology. 2020. https://doi.org/10.1016/S2665-9913(20)30121-1

48. Marini JJ, Gattinoni L. Management of COVID-19 respiratory distress. Jama. 2020. https://doi.org/10.1001/jama.2020.6825

49. Meng J, Xiao G, Zhang J, He X, Ou M, Bi J, et al. Renin-angiotensin system inhibitors improve the clinical outcomes of COVID-19 patients with hypertension. Emerging microbes \& infections. 2020;9(1):757-60. https://doi.org/10.1080/22221751.2020.1746200

50. Phua J, Weng L, Ling L, Egi M, Lim C-M, Divatia JV, et al. Intensive care management of coronavirus disease 2019 (COVID-19): challenges and recommendations. The Lancet Respiratory Medicine. 2020. https://doi.org/10.1016/S2213-2600(20)30161-2

51. Velavan TP, Meyer CG. The COVID-19 epidemic. Tropical medicine \& international health. 2020;25(3):278. https://doi.org/10.1111/tmi.13383

52. Hu Y, Sun J, Dai Z, Deng H, Li X, Huang Q, et al. Prevalence and severity of corona virus disease 2019 (COVID-19): A systematic review and meta-analysis. Journal of Clinical Virology. 2020:104371. https://doi.org/10.1016/j.jcv.2020.104371 